\title{
Identifikasi Kekuatan, Kelemahan, Peluang, Ancaman PT. Prudential Provinsi Riau
}

\author{
NOFRIZAL $^{1}$; EFRITA SOVIYANTI ${ }^{2}$ \\ 1,2 Universitas Lancang Kuning, \\ J1. Yos Sudarso KM 08 Rumbai-Pekanbaru, Indonesia, 28265 \\ E-mail: Nofrizalfe@unilak.ac.id efritasoviyantihrp@gmail.com
}

\begin{abstract}
Insurance business in Riau province growing and developing, every company including PT. Prudential Indonesia is trying to launch a new strategy to capture the available market share, but whether the strategy has been made is in line with current external and internal business circumstances. For that required identification of opportunities, threats, strengths, weaknesses are good for preparing the right strategy. The purpose of this study is to identify the shade, threats, strengths, weaknesses of PT. Prudential Indonesia in Riau province. This research method uses descriptive analysis with indentification stage that is Eksteral factor analysis (EFAS), Five force porter and Internal factor analysis (IFAS), VRIO, and Resource base view. The results of this study show that the opportunities, threats, strengths, and weaknesses of PT. Prudential Indonesia is in good condition where the value of strength is greater than the value of weakness and the value of opportunity is greater than the threat so it can make some growth strategy to seize market share in Riau Province.
\end{abstract}

Keywords: SWOT, Management Strategy, Insurance

Menganalisis lingkungan Ekternal dan Internal merupakan faktor penting agar strategi dapat berhasil, lingkungan eksternal digunakan untuk menemukan peluang dan ancaman yang datang dari luar organisasi perusahaan, sedangkan lingkungan internal digunakankan untuk menemukan kekuatan dan kelemahan yang berasal dari dalam perusahaan. Dunia asuransi di provinsi Riau saat ini tidak lepas dari pengaruh lingkungan ekternal dan internal dimana masing-masing perusahaan asuransi terus membuat strategi-strategi baru berdasarkan kondisi lingkungan tersebut. Salah satu fakta penting strategi yang sudah dilakukan Prudential Indonesia adalah (Berdasarkan pada 31 Desember 2014),

Prudential Indoenesia mendirikan kantor pusat di Jakarta untuk menambah kekuatan jangkauan dengan 6 kantor Pemasaran di Bandung, Semarang, Surabaya, Denpasar, Medan, dan Batam), serta 380 kantor Pemasaran Mandiri (KPM) di seluruh Indonesia, sedangkan di provinsi Riau PT. Prudential memiliki 12 kantor cabang dengan 2000 agen pemasaran yang sudah memiliki lisensi dari AAJI (Asosiasi Asuransi Jiwa Indonesia).

Selain itu pada saat ini beberapa strategi yang sudah dilakukan untuk meningkatkan kemampuan (SDM) para agen dengan membuat program mingguan seperti Monday Meeting (M3), One day seminar, dan Pru sales academy. Adapun bentuk program kegiatan ini meliputi motivasi dan pelatihan-pelatihan tentang marketing dan jenjang karir tujuan dari program ini untuk mengurangi kelemahan agar dapat bersaing dengan perusahaan asuransi jiwa yang lain, Seperti yang disampikan oleh ketua Asosiasi Asuransi Umum Indonesia (AAUI) cabang pekanbaru, Budi Hendro Tjahjono jumlah asuransi di Provinsi riau sebanyak 53 buah perusahaan diantaranya adalah Zurich, Astralife, Manulife, Sinarmas, Allianz, Generel, AOI, Axxa Mandiri, jiwasraya dan lain-lain.

Dengan semakin banyaknya perusahaan yang akan merebutkan pangsa pasar yang masih luas dan potensial. Maka akan menimbulkan persaingan, persaingan tentu memiliki tujuan sebuah kemenangan dan untuk dapat menang 
dalam persaingan dibutuhkan strategi. Menurut (David, 2016) Bahwa "strategi perusahaan merupakan rumusan perencanaan komprehensif tentang bagaimana perusahaan akan mencapai misi dan tujuanya. menurut (Stonehouse \& Snowdon, 2007) Tujuan akhir strategi bersaing adalah untuk menanggulangi kekuatan lingkungan demi kepentingan perusahaan dan dibutuhkan taktik untuk dapat memenangkan persaingan dan mempertahankan posisi pangsa pasar sehingga persaingan kualitas, harga, promosi, produk dan pelayanan tidak biasa terelakan yang membutuhkan investasi yang cukup besar. Sebelum strategi bersaing dibuat maka diperlukan identifikasi tentang bagaimana peluang, acaman, kekuatan, kelemahan PT. Prudential di Provinsi Riau menurut (SANTOSO, 2015)

Identifikasi ini dapat dilakukan dengan menggunakan SWOT. SWOT merupakan (Taufik \& Suprajang, 2016) Analisis dimulai dengan kajian terhadap faktor-faktor eksternal dengan melakukan analisis peluang dan ancaman, baru kemudian diikuti dengan kajian kondisi internal perusahaan berupa kekuatan dan kelemahan. Urutan analisis semacam ini dilandasi oleh adanya kenyataan bahwa di era 1990-an perubahan dan turbulensi lingkungan menjadi semakin penting, jauh melebihi perubahan lingkungan internal, karena itu kita harus mulai dari luar, baru ke dalam. Dengan kata lain kita menggunakan pendekatan outside-in, bukan inside- out.

\section{METODE}

Penelitian ini menggunakan metode kualitatif. Menurut (Sugiyono, 2012): 38) mengemukakan bahwa metode kualitatif mengambarkan dan memahami makna dibalik data-data yang tampak. Teknik dalam pengumpulan data penelitian menggunakan teknik wawancara, observasi dan studi pustaka. Metode menganalisis data menggunakan tahapan Analisis SWOT yaitu dimulai dari lingkungan eksternal (EFAS)
PEST and Five Force Porter, Analisis lingkungan internal (IFAS), VRIO, Resource base View. Lihat gambar 1 Gambar 1.

Tahapan Identifikasi lingkungan eksternal dan internal Prudential

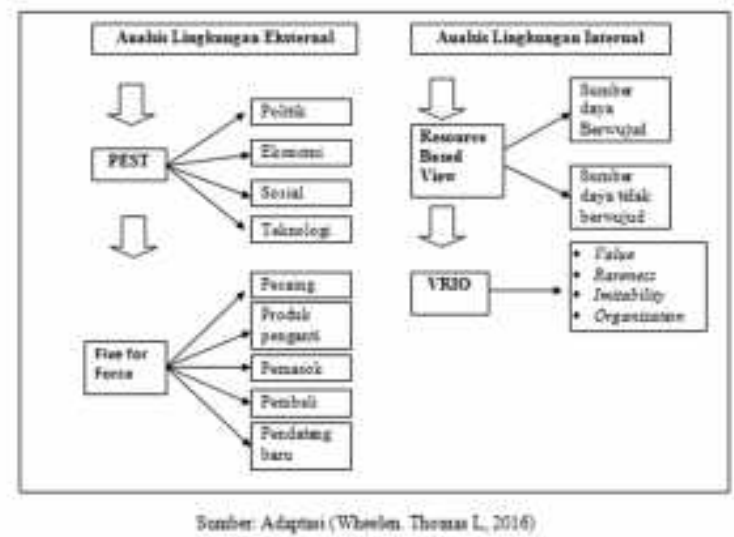

HASIL

Analisis Lingkungan Eksternal (EFAS) - Politik

Politik sangat berkaitan dengan kebijakan yang dibuat oleh pemerintah yang mengatur bagaimana berjalannya perusahaan tersebut berada. Kebijakan ini dibuat oleh DPRD pada daerah tersebut. Di provinsi Riau menurut data (Gultom, 2016) nilai indeks dari variabel "Peran Birokrasi Pemerintah" di Provinsi Riau pada tahun 2015 adalah sebesar 29,78, turun secara signifikan sebesar 70,22 poin jika dibandingkan dengan capaian tahun 2014 yaitu sebesar 100,00 . Penurunan yang sangat signifikan ini dikarenakan pada tahun 2015 terjadi perubahan indikator yang menyusun variabel tersebut

\section{- Ekonomi}

PDRB per-kapita Provinsi Riau menunjukkan peningkatan dari tahun ke tahun, seiring dengan kenaikan nilai nominal PDRB dan jumlah penduduk. Indikator ini menunjukkan bahwa secara ekonomi setiap penduduk Riau rata-rata mampu menciptakan PDRB atau (nilai tambah) sebesar nilai perkapita di masingmasing tahun tersebut. Sedangkan dari pendapatan pemerintah kabupaten/kota seluruh Provinsi Riau di tahun 2014 mengalami peningkatan dibandingkan

p.ISSN: $2407-800 \mathrm{X} \quad$ e.ISSN: $2541-4356$ 
tahun sebelumnya, dengan total pendapatan 24.305 triliun. Berdasakan pangsa pasar asuransi Indonesia yang masih luas dengan perbandingan $\mathrm{PDB} \mathrm{cmn} 1 \%$ aja yang dibandingkan Singapore dibagian asuransi bisa menyumbangkan 5\% dari PDB. maka Indonesia merupakan salah satu pangsa pasar yang bagus dan menggiurkan untuk 5 tahun kedepan untuk merupakan suatu data yang sangat menarik untuk investasi membangun perusahaan asuransi baru di indonesia maupun dari investor asing atau investor lokal untuk mencoba mencari keuntungan dalam bidang asuransi sehingga peluang untuk pendatang baru cukup besar

- Sosial Budaya

Pada tahun 2010-2015 dan bila dilihat menurut kabupaten/kota, Kabupaten Pelalawan, Kabupaten Rokan Hulu, dan Kabupaten Siak adalah tiga kabupaten/kota dengan LPP terbesar. Sementara itu, Kabupaten Indragiri Hilir dan Kabupaten Kepulauan Meranti adalah dua kabupaten/kota dengan LPP terkecil. Dari 12 kabupaten/kota di Riau, terdapat 6 kabupaten/kota dengan LPP di atas angka provinsi, dan sisanya (6 kabupaten/kota) di bawah angka Provinsi. Untuk lebih lengkapnya posisi kabupaten/kota.

\section{- Teknologi}

Provinsi riau sudah menjalankan system elektronik dalam kegiatan pemerintahaan (EGovernment) (UtusanRiau, 2016) melalui pengembangan E-Government dilakukan penataan system manajemen dan proses kerja dilingkungan pemerintah dengan mengoptimalkan pemanfaatan teknologi informasi mencakup 2 aktivitas yaitu pengelolahan data dan pengelolahan informasi

\section{- Five Force Porter}

1. Persaingan. Persaingan sudah banyak diindustri asuransi jiwa di provinsi Riau menurut (Daftar Perusahaan, 2012) ada 45 asuransi jiwa di provinsi dari skala Global dan Nasional. Sedangkan menurut (AAJI, 2016) pesaing terketat dari prudential berdasarakan asuransi terbaik menurut majalah investor adalah Jiwa
Seraya, PT Panin Dai-ichi Life, PT BNI Life Insurance, PT Asuransi Jiwa Adisarana Wanaartha, serta PT Asuransi Jiwa Inhealth Indonesia.

2. Pemasok. Pengaruh pemasok tidak memiliki pengaruh yang besar karena untuk menyediakan kebutuhan Prudential Indonesia dibidang investasi sudah diatur oleh (OJK, 2011) Dengan mengawasi supplier dari perusahaan asuransi lebih ke custodian bank.

3. Pengaruh substitusi terhadap asuransi, apakah konsumen dapat memperoleh barang substitusinya dengan mudah? Semakin banyak dan dekat barang substitusi, maka pelanggan juga bisa beralih dengan mudah. Force ini dipengaruhi oleh beberapa faktor diantaranya switching cost, kecenderungan untuk substitusi, diferensiasi produk, dan lainnya. Subtitusi dari asuransi di Indonesia adalah: Ketatnya persaingan bank yang menawarkan berbagai macam produk seperti, deposito dengan bunga tinggi.

4. Pembeli. Pengaruh pembeli terhadap prudential cukup besar karena di pengaruhi oleh mudahnya pembeli pindah keasuransi lain dengan alasaan seperti tidak merasa puas dengan pelayanan yang di berikan, hasil wawancara kepada pimpinan divisi Prudential di provinsi Riau bahwa tinggkat nasabah jatuh tempo untuk membayar premi setiap bulan juga cukup tinggi setiap bulannya. Selain itu pembeli produk- produk asuransi Prudential di Provinsi Riau merupakan pembeli perorangan bukan pembeli dalam bentuk kelompok atau perusahaan sehingga tidak perlu dilayani dengan maksimal cukup hanya dilayani secara invidual sehingga tidak mengeluarkan dana yang besar untuk memberikan pelayanan. 
5. Pendatang baru. Berdasakan pangsa pasar asuransi Indonesia yang masih luas dengan perbandingan PDB $\mathrm{cmn}$ $1 \%$ aja yang dibandingkan Singapore dibagian asuransi bisa menyumbangkan 5\% dari PDB. maka Indonesia merupakan salah satu pangsa pasar yang bagus dan menggiurkan untuk 5 tahun kedepan untuk merupakan suatu data yang sangat menarik untuk investasi membangun perusahaan asuransi baru di indonesia maupun dari investor asing atau investor lokal untuk mencoba mencari keuntungan dalam bidang asuransi sehingga peluang untuk pendatang baru cukup besar.

\section{Analisis Lingkungan Internal (IFAS)}

Untuk mengidentifikasi sumber daya yang akan memberikan advantage bagi Prudential Indonesia di provinsi Riau kami menggunakan Value Chain Analysis dikombinasikan dengan Resource Based View of The Firm dan VRIO Framework lihat gambar Value chain. Berdasarkan gambar diatas maka untuk menentukan faktor-faktor kekuatan dan kelemahan Prudential di Provinsi Riau berdasarkan pendekatan resource base view dan VRIO (Value, Rarity, Imitability and Organization). Maka hasil kerangka analisis VRIO diatas akhirnya bisa disimpulkan kekuatan dan kelemahan Prudential di Provinsi Riau fasilitas, One day Semina, Pelatihan SDM dengan UI, Reward System, Career, Cabang, Total Aset, PRUsales academy, dan SFA (Sales Force Automation). Berdasarkan tabel IFAS setelah di analisis dan dihitung ditemukan faktor yang paling berpengaruh terhadap Prudential di Provinsi Riau yaitu Sheria Income, Good Risk-based Capital (RBC), M3 (mondey Meeting), Pengembangan SDM, dan Total asset.

\section{Gambar 2. Value Chain PT. Prudential Indonesia Provinsi Riau}

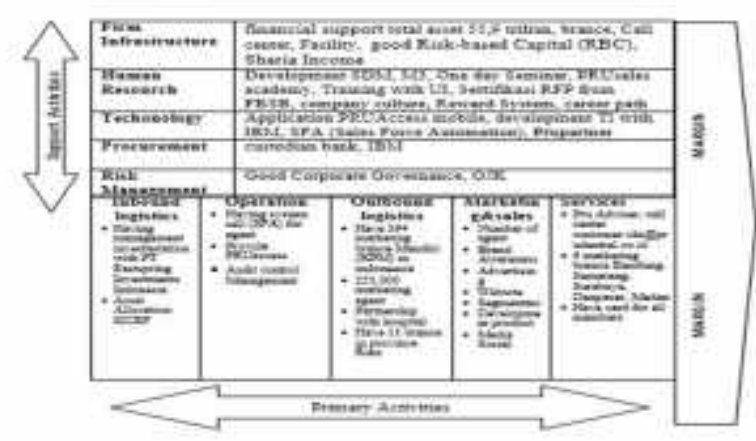

Berdasarkan gambar 2 diatas setelah di lakukan identfikasi mengunakan value chain berdasarkan dengan keadaan internal Prudential maka ditemukan beberapa data tentang keadaaan fasilitas, sumber daya manusia, kekuatan teknologi procurement, dan resiko manajemen. Dari data-data tersebut akan digunakan untuk menentukan apakah factor-faktor tersebut memiliki nilai untuk digunakan sebagai factor untuk bersaing di industry asuransi atau tidak. Untuk menentukan factor-faktor tersebut memiliki keunggulan bersaing maka digunakan kerangka analisis VRIO seperti tabel 1 dibawah ini.

Tabel 1. Tabel Kerangka Analisis VRIO

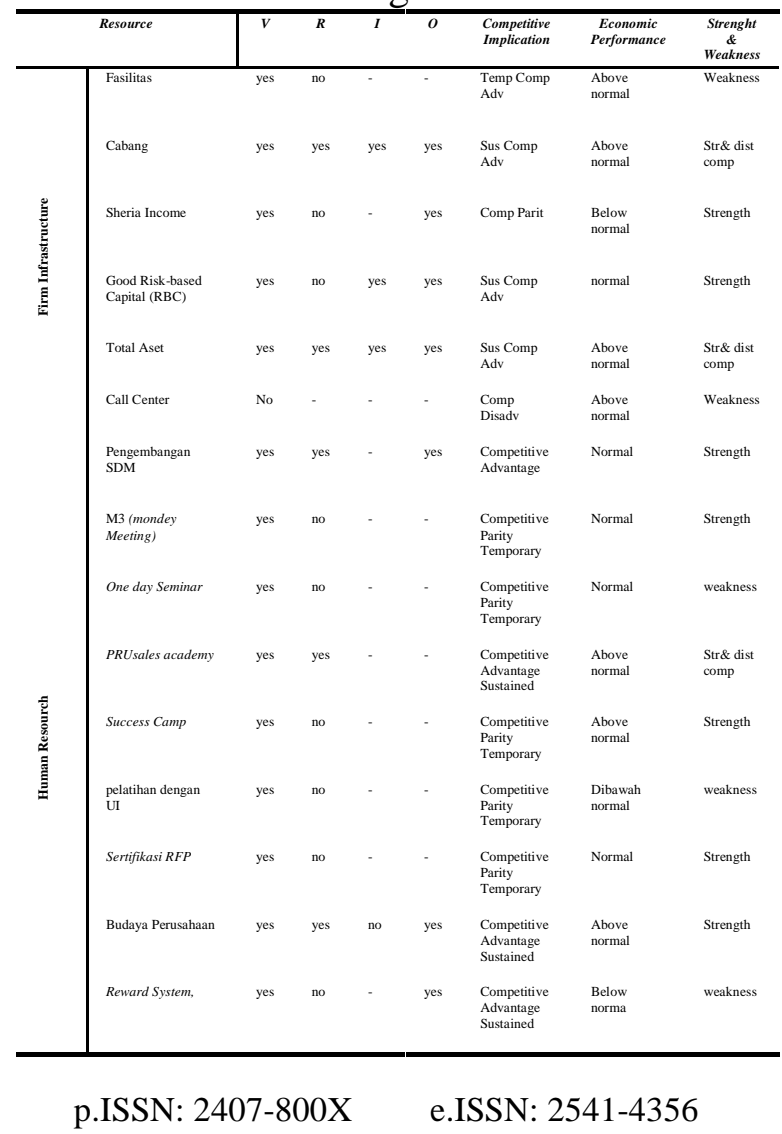




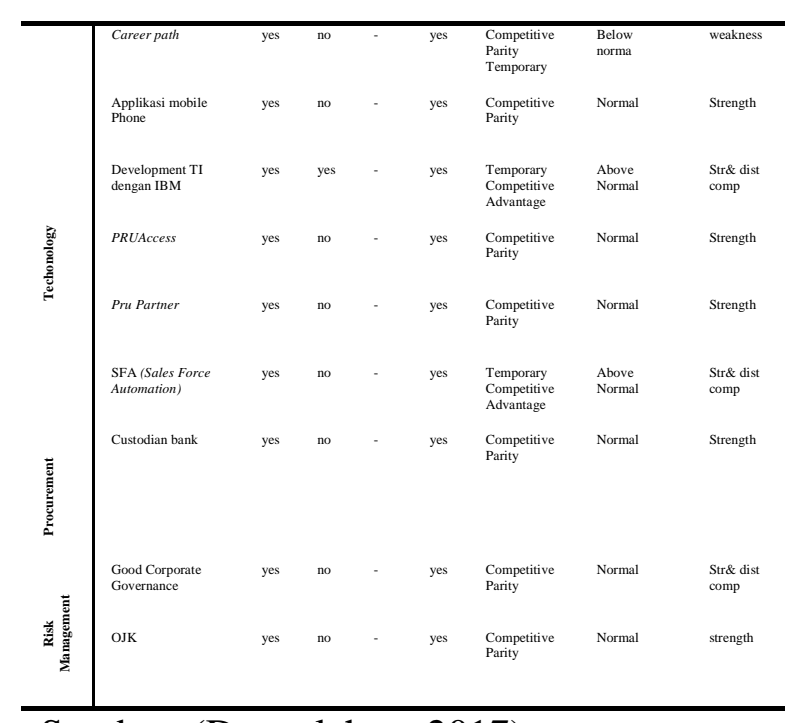

Sumber: (Data olahan, 2017)

Berdasarkan table 2 diatas untuk menentukan faktor-faktor kekuatan dan kelemahan Prudential di Provinsi Riau berdasarkan pendekatan resource base view dan VRIO (Value, Rarity, Imitability and Organization). Maka hasil dari tabel kerangka analisis VRIO diatas akhirnya bisa disimpulkan kekuatan dan kelemahan Prudential di Provinsi Riau seperti yang terlihat di table 2 dibawah ini.

Tabel 2. Tabel kekuatan dan kelemahan PT. Prudential Life Indonesia di Provinsi Riau

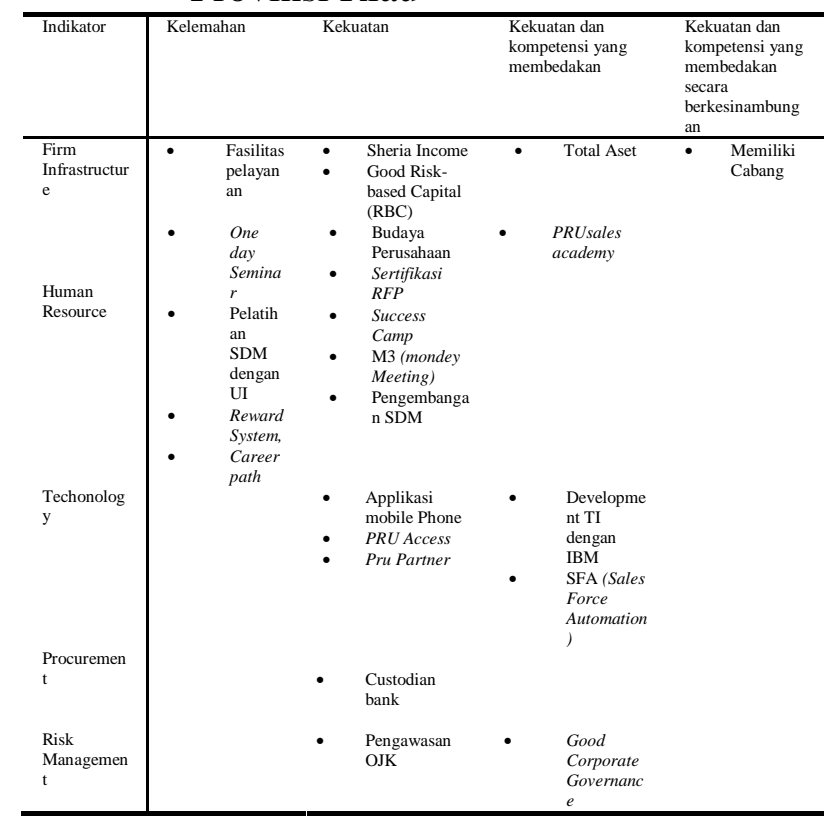

Sumber: (Data olahan, 2017)

Berdasarkan tabel 2 diatas ditemukan beberapa kelemahan seperti fasilitas pelayanan, one day seminar, pelatihan SDM, dan career path(Jenjang karir), namun dibalik kelemahan yang dimiliki Prudential di Provinsi riau juga memiliki kekuatan seperti, pendapatan dari produkproduk syariah, sudah memiliki sistem Pru Access dan Pru Patner, sudah diawasi OJK dan lain-lain. Sedangkan kekuatan yang membedakankan dari pesaing dan berkesinambungan adalah SFA (Sales Force Automation), GCG, Pru sales,Total asset, dan memiliki cabang yang banyak dibandingkan pesaing.

Setelah di temukan keadaan dari lingkungan internal dan eksternal diatas maka kita ditemukan Peluang, ancaman, kekuatan, kelemahan Prudential di Provinsi Riau seperti pada tabel 3 dibawah ini.

Tabel 3. Rangkuman Peluang, Ancaman, Kekuatan, Kelemahan PT. Prudential Provinsi Riau

\begin{tabular}{|c|c|c|c|}
\hline \multirow[t]{2}{*}{ No } & $\begin{array}{c}\text { Daftar Peluang dan } \\
\text { Ancaman }\end{array}$ & No & $\begin{array}{c}\text { Daftar Kekuatan dan } \\
\text { Kelemahan }\end{array}$ \\
\hline & Peluang & & Kekuatan \\
\hline 1 & Jumlah penduduk & 1 & Sheria Income \\
\hline 2 & $\begin{array}{l}\text { Tren masyarakat tentang } \\
\text { jaminan masa depan }\end{array}$ & 2 & $\begin{array}{l}\text { Good Risk-based Capital } \\
\text { (RBC) }\end{array}$ \\
\hline 3 & $\begin{array}{l}\text { Tingkat pengetahuan } \\
\text { tentang ansuransi }\end{array}$ & 3 & Budaya Perusahaan \\
\hline 4 & Pertumbuhan ekonomi & 4 & Sertifikasi RFP \\
\hline 5 & $\begin{array}{l}\text { Kemajuan teknologi } \\
\text { informasi }\end{array}$ & 5 & Success Camp \\
\hline 6 & $\begin{array}{l}\text { Tingkat kepercayaan } \\
\text { konsumen tentang } \\
\text { asuransi }\end{array}$ & 6 & M3 (mondey Meeting) \\
\hline 7 & $\begin{array}{l}\text { Gaya hidup Budaya } \\
\text { masyarakat yang } \\
\text { individual }\end{array}$ & 7 & Pengembangan SDM \\
\hline 8 & $\begin{array}{l}\text { Luasnya jumlah wilayah } \\
\text { di provinsi Riau }\end{array}$ & 8 & Applikasi mobile Phone \\
\hline \multirow[t]{6}{*}{9} & $\begin{array}{l}\text { Biaya kesehatan yang } \\
\text { mahal }\end{array}$ & 9 & PRUAccess \\
\hline & & 10 & Pru Partner \\
\hline & & 11 & Custodian bank \\
\hline & & 12 & Cabang \\
\hline & & 13 & Total aset \\
\hline & & 14 & SFA (Sales Force Automation) \\
\hline No & Ancaman & No & Kelemahan \\
\hline 1 & $\begin{array}{l}\text { Jumlah pesaing di } \\
\text { industri asuransi }\end{array}$ & 1 & Fasilitas \\
\hline 2 & $\begin{array}{l}\text { Image masyarakat } \\
\text { tentang kualitas } \\
\text { pelayanan asuaransi }\end{array}$ & 2 & Reward System \\
\hline 3 & $\begin{array}{l}\text { Kebijakan pemerintah } \\
\text { tentang asuaransi }\end{array}$ & 3 & $\begin{array}{l}\text { Pelatihan dengan Universitas } \\
\text { Indonesia }\end{array}$ \\
\hline 4 & $\begin{array}{l}\text { Produk penganti } \\
\text { asuransi }\end{array}$ & 4 & Career path \\
\hline 5 & Pendatang baru & 5 & $\begin{array}{l}\text { Kapasitas tenaga pemasaran } \\
\text { (Agen) }\end{array}$ \\
\hline
\end{tabular}

Sumber: (Data olahan, 2017)

Pada tabel 3 diatas masih banyak data yang belum sempurna didapatkan selama penelitian dan observasikan dilakukan namun secara keseluruhan

p.ISSN: $2407-800 X \quad$ e.ISSN: $2541-4356$ 
keadaan Prudential di Provinsi Riau masih dalam keadaan baik, hal ini dapat dilihat pada masih aktifnya beberapa cabang prudential di provinsi Riau bahkan pada tahun 2015 membuka cabang baru di Jl. Harapan raya. Pada faktor kelemahan pada saat ini terus dilakukan perbaikan-perbaikan seperti fasilitas, reward system dengan membuat program bonanza agar dapat memotivasi karyawan dan meningkatkan hasil dari target pendapatan premi yang sudah ditetapkan di masing-masing cabang. Selain itu hasil penghitungan menggunakan analisis SWOT menunjukan posisi strategi Prudential berada pada nilai antara faktor eksternal dan internal Prudential di Provinsi Riau dimana selisish dari peluang dan ancaman adalah 0.174 sedangkan nilai selisih dari kekuatan dan kelemahan adalah 1.531. Jadi posisi Prudental berada pada strategi pertumbuhan agersif.

\section{PEMBAHASAN}

PT Prudential Life Assurance (Prudential Indonesia) di provinsi Riau sudah cukup lama beridiri dan menjadi pemimpin pasar di provins ini. Namun dengan perjalanan waktu pengaruh lingkungan eksternal dan internal tidak dapat di hindari sehingga membuat Prudential di Provinsi Riau menyusun beberapa strategi seperti dijelaskan pada bagian latar belakang. Setelah dilakukan analisis dan observasi pada bagian hasil maka ada beberapa hal yang perlu dibahas tentang peluang, ancaman, kekuatan, dan kelemahan.

Pada bagian peluang dapat dilihat bahwa jumlah penduduk diprovinsi Riau yang cukup banyak yaitu 5.543.031 jiwa ditambah total pendapatan daerah yang cukup besar yaitu 24.305 triliun maka ini bisa menjadi indikator peluang yang besar bagi prudential untuk menangkap peluang pasar yang masih terbuka lebar, serta dengan berdirnya BPJS Kesehatan dan BPJS Ketenagakerjaan menambah pengetahuan masyarakat tentang pentingya berasuransi, walaupun dari hasil kualitas layanan masih banyak yang mengeluh dengan pelayanan BPJS yang didirikan oleh pemerintah, padahal hasil penelitian dari (Putranti, 2015) dalam mempertahan loyalitas strategi para agen Prudential harus memberikan informasi berkala kepada nasabah, 2. Service quality agen, 3. Membangun hubungan pribadi dengan nasabah. Mengingat masih banyaknya masyarakat yang belum memahami pentingnya berasuransi, menjadi peluang bagi para pemasar untuk memberikan edukasi asuransi kepada masyarakat hingga bisa memperluas bisnis asuransi syariah.

Ancaman di dalam bisnis tidak bisa dihindari tergantung bagaimana perusahaan menyikapi ancaman tersebut(Faruq \& Usman, 2016), berdasarkan ancaman yang di hadapi oleh Prudential di Provinsi Riau pengaruh pesaing tidak bisa di hindari, jika semakin banyak pesaing maka akan semakin sedikit kemungkinan untuk mendapatkan keuntungan yang besar(David, 2016), ancaman pesaing juga terjadi pada penelitian yang dilakukan oleh (Taufik \& Suprajang, 2016) dengan faktor yang paling berpengaruh yaitu pesaingan antara industri rokok di kabupaten tulungagung. Untuk itu ancaman dapat diminimalkan dengan menggunakan kekuatan dan peluang yang dimiliki (Nofrizal, 2016) penelitian tentang BMT Al-Ittihad Kota Pekanbaru.

Kekuatan Prudential di Provinsi Riau sudah diakui memiliki kekuatan yang luar biasa besar dapat dilihat dari jumlah asset yang dimiliki, jumlah agen yang berlesensi, jumlah cabang dan lain-lain. Namun dari semua itu hingga saat ini Prudential dapat mengelola kekuatan dengan baik, hal ini terbukti dengan masih mendapatkan pengahargaan-pengahargaan baik berskala international dan nasional. Beberapa keunggulan-keungglan harus di komunikasi dengan baik kepada masyarakat. Menurut (I Wayan Alit Mahendra Putra A N \& Sukaatmadja, 2016) dalam hasil penelitianya bahwa kepuasan konsumen, kepercayaan, dari pemasaran melalui mulut-kemulut memberikan dampak postif terhadap BPJS Ketenagakerjaan di bali. Komunikasi juga

p.ISSN: 2407-800X e.ISSN: 2541-4356 
dapat dilakukan dengan menggunkan media social dan elektronik menurut (Constantinides, 2014) social media dapat merubah kekuatan pasar. Dengan kekuatan yang dimiliki Prudential dapat menggunkanya untuk meningkatkan kepercayaan calon nasabah dan nasabah agar tetap menjadi nabasah yang loyal terhadap Prudential di Provinsi Riau, sampai saat ini Prudential masih dipercayai oleh nasabahnya. Dari sudut kelemahan memang masih ada ditemukan misalnya dalam hal fasilitas, namun dari nilai keseluruhan ini tidak berpengaruh signifikan terhadap Prudential, hanya saja diperlukan perhatian khusus seperti dalam motivasi agen, karena dari beberapa wawancara yang dilakukan kepada agen Prudential di Provinsi Riau masih banyak menjadi agen masih setegahsetengah/ sampingan saja untuk menambah penghasilan. Adapun dampak dari tidak fokusnya agen terhadap profesinya sebagai agen maka kualitas pelayanan terhadap pelanggan juga tidak maksimal sedangkan menurut (Susanti, Warso, \& Haryono, 2016) bahwa dalam hasil penelitian agen merupakan penyampai pesan dari perusahan melalui mulut-kemulut (word of mouth) untuk meninmbukan kepercayaan kepada nasabah dan calon nasabah. Padahal unjung tombak dari perusahan asuransi adalah pada agen (Castronovo, 2012) . Oleh karena itu prudential terus berusaha untuk menyusun dan mengevaluasi strategi SDM agar maksimal memberikan pelayanan kepada nasabahnya seperti program M3, One day Seminar, dan penghargaan.

\section{SIMPULAN}

Industri asuransi tidak bias lepas dari pengaruh lingkungan eksternal dan internal termasuk Prudential Indonesia di Provinsi Riau. Setiap strategi yang dibuat tentu harus berdasarkan keadaan lingkungan yang terjadi sekarang. Hampir dari seluruh temuan dari indentifikasi pelaung, ancaman, kekuatan, dan kelemahan semua lebih banyak dipengaruhi dari faktor eksternal di bandingkan factor internal, karena faktro internal pada dasarnya mengikuti keadaan eksternal di luar perusahaan. Seperti factor peluang jumlah penduduk, pendapataan Prudential Indonesia berusahaan untuk mengkap dan menjadi pemimpin pangsa pasar dengan cara merekrut agen sebanyakbanyaknya dan menambah/ mendirikan cabang-cabang baru hingga saat ini berjumlah 12 cabang. Di factor ancaman membuat prudential berusaha memberikan perlawanan dengan terus menawarkan produk-produk baru seperti produk-produk asuransi sudah Unit-Link seperti, Pru_Syariah, Pru_link dan lain-lain yang memiliki fasiltas tabungan sekaligus ada pelindungan jiwa didalamnya. Jadi secara umum keadaan Pelauang, ancaman, kekuatan, dan kelemahan Prudential Indonesia di Provinsi Riau dalam keadaan baik, sekarang bagaiman Prudential mengelola semua itu untuk dapat menjadi senjata yang efektif untuk memenangkan persaingan.

Kedepan Prudential Indonesia harus memberikan pelayanan yang tebaik dengan yang kekuatan yang dimiliki sekarang serta selalu memberikan informasi terbaru tentang investasi dan pengelolaan keuangan nasabah wujud dari ketransfaranan informasi, tujuannya adalah untuk memberikan keyakinan terhadap nasabah bahwa Prudential merupakan perusahaan Asuransi Jiwa terbaik di Indonesia. selain itu pemanfaatan media social tidak bisa di hindari lagi, semoga dengan semakin majunya teknologi informasi maka akan membantu Prudential Indonesia mengkomunikasikan produk, penghargaan, prestasi kepada calon nasabah dan nasabah.

\section{DAFTAR RUJUKAN}

Aaji. (2016). Asuransi Terbaik 2016 Versi Majalah Investor. Retrieved April 10, 2017, From Http://Www.Aaji.Or.Id/Newsevent /Asuransi-Terbaik-2016-VersiMajalah-Investor

Castronovo, C. (2012). Social Media In An Alternative Marketing

p.ISSN: $2407-800 \mathrm{X}$ e.ISSN: 2541-4356 
Communication Model. Journal of

Marketing Development And Competitiveness Vol., 6(1), 117131.

Constantinides, E. (2014). Foundations Of Social Media Marketing. Procedia Social And Behavioral Sciences, 148, 40-57. Https://Doi.Org/10.1016/J.Sbspro.2 014.07.016

Daftar Perusahaan. (2012). Daftar Perusahaan Asuransi Jiwa. Retrieved April 10, 2017, From Http://Www.Daftarperusahaan.Com /Bidang/Asuransi-Jiwa

David, F. R. D. And F. R. (2016). Strategic Management: A Competitive Advantage Approach, Concepts And Cases. (15 Edition). England: Pearson-Prentice Hall.

Faruq, M. A., \& Usman, I. (2016). Penyusunan Strategi Bisnis Dan Strategi Operasi Usaha Kecil Dan Menengah Pada Perusahaan Konveksi Scissors Di Surabaya. Jurnal Manajemen Teori Dan Terapan | Journal of Theory And Applied Management, 7(3).

Gultom, A. (2016). Profil Demokrasi Indonesia Di Provinsi Riau Tahun 2015. Pekanbaru.

I Wayan Alit Mahendra Putra A N, M. W., \& Sukaatmadja. (2016). Pengaruh EServqual Terhadap Customer Satisfaction , Trust, Dan Word Of Mouth Peserta Bpjs Ketenagakerjaan I Wayan Alit Mahendra Putra A N 1 Fakultas Ekonomi Dan Bisnis Universitas Udayana ( Unud ), Bali , Indonesia Pendahuluan Jaminan Sosial Telah Diter. E-Jurnal Ekonomi Dan Bisnis Universitas Udayana, 11(November), 3647-3682.

Jurnal Daya Saing
Nofrizal. (2016). Chosen Marketing Strategy Of Bmt Al-Ittihad. South East Asia Journal Of Contemporary Business, Economics And Law, 11(2), 10-17.

Ojk. (2011). Kustodian. Retrieved April 10, 2017 , From Http://Www.Ojk.Go.Id/Id/Kanal/P asar-Modal/Regulasi/KlasifikasiBapepam/Lembaga-PenunjangPasarModal/Pages/Kustodian.Aspx

Putranti, O. Y. (2015). Strategi Pemasaran Agen Pt. Prudential Dalam Mempertahankan Loyalitas Nasabah Prulink Syariah. Uin Syarif Hidayatulah Jakarta. Retrieved From Http://Repository.Uinjkt.Ac.Id/Ds pace/Bitstream/123456789/30099/ 1/Octovina Yesi Putranti-Fsh.Pdf

Santoso, B. (2015). Analisis Swot Dalam Menentukan Strategi Pemasaran Bisnis Indomaret Cabang Pabelan. Retrieved From Http://Eprints.Ums.Ac.Id/37711/

Stonehouse, G., \& Snowdon, B. (2007). Competitive Advantage Revisited: Michael Porter On Strategy And Competitiveness. Journal of Management Inquiry, 16(3), 256273.

Https://Doi.Org/10.1177/10564926 07306333

Sugiyono, P. (2012). Metode Penelitian Kuantitatif, Kualitatif Dan $R \& D$. Bandung (Cetakan Ke). Bandung: Alfabeta.

Susanti, A., Warso, M. M., \& Haryono, A. T. (2016). Pengaruh Layanan, Reputation, Preference Dan Word Of Mouth Terhadap Repurchase Intention (Studi Kasus Pada Pt. Ntronik Lintas Nusantara, p.ISSN: $2407-800 X \quad$ e.ISSN: 2541-4356 
Semarang). Journal Of

Management, 2(2).

Taufik, M. I., \& Suprajang, S. E. (2016).

Analisis Threats, Opportunity,

Weakness, Strengths (Tows)

Sebagai Landasan Dalam

Menentukan Strategi Pemasaran

Pada Pr. Semanggimas Agung

Boyolangu Kabupaten

Tulungagung. Riset Mahasiswa

Ekonomi (Ritmik), 2(1).

Utusanriau. (2016). Seluruh Skpd Riau Telah

Terkoneksi Dengan E-Government.

Retrieved April 8, 2016, From

Http://M.Utusanriau.Co/Index.Php?/

Det/27873/Seluruh-Skpd-Riau-

Telah-Terkoneksi-Dengan-Sistem/

Wheelen. Thomas L, H. J. D. (2016).

Strategic Management And Business

Policy Toward Global

Sustainability. (13th Edition, Ed.).

Pearson. 